\title{
Sustaining collaborative preschool partnerships and the challenges of educating the whole child
}

\author{
Ryan Alverson ${ }^{*^{*}} \mathbb{0}$, Laken Ginn ${ }^{2}$ and Jaesook Gilbert ${ }^{3}$
}

\author{
*Correspondence: \\ alversonj1@nku.edu \\ 1 Department of Teacher \\ Education, MEP 273, Nunn \\ Drive, Highland Heights, KY \\ 40199, USA \\ Full list of author information \\ is available at the end of the \\ article
}

\begin{abstract}
Introduction: Our study examined whole-child preschool programming from a policy perspective. We suggest that whole-child wellness must include sustainable approaches that are systematic and holistic approaches for educating children. The Preschool Partnership Grant was a means of funding preschool districts, who successfully applied for the grant across our state to initiate, continue, and sustain quality programming with their respective local preschool partners. Funding also enabled districts to increase access to quality programming while fostering kindergarten readiness in participating children.
\end{abstract}

Case description: We conducted a case study by analyzing data provided by district Preschool Partnership Grantees. Data included quantitative measures of district and partner preschools and open-ended items describing professional development opportunities, holistic interventions, and effective preschool activities afforded by grant funding.

Results: Grant recipients $(n=79)$ reported that they engaged in a number of different public and private partnerships. They reported being able to serve more children due to grant funding, and gave a variety of reasons for serving more children, with improved collaboration being the most reported reason. District grantees also indicated increased consultation, intervention services, and professional development opportunities through grant funding. Finally, they reported on key challenges they faced during the grant period.

Discussion and evaluation: Data suggested that school districts recognized the importance of collaboration, trust, and relationship building among districts, partners, and families. Descriptive data indicated the importance of sustaining quality programming during the grant period. Districts also clearly voiced their appreciation of the importance of relationships and collaboration among key stakeholders who touched the lives of children enrolled in the grantee districts.

Conclusions: Our study suggests that early childhood policy should enable systematic and sustainable partnerships that approach preschool programming from a holistic perspective.

Keywords: Early childhood funding policy, Holistic wellness, Case study, Quality preschool programming 


\section{Background}

Holistic, or "whole-child", (Puma et al. 2010) approaches are those practices that support the physical, social, and emotional developmental needs of children, and this support carries over into the child's academic skills and other more traditional indicators of educational success (Crosnoe et al. 2015). In this paper, we examine the "whole-child" from a policy perspective and suggest that early childhood approaches should be sustainable, systematic, and holistic, involving all of the people who touch the life of the child. To sustain such programs, there need to be a consistent source of funding to spark, build, and maintain the collaborative efforts that make such holistic approaches to early childhood education possible.

Numerous studies have documented that high-quality prekindergarten education can impact students into their high school career and beyond (Meloy et al. 2019). Such benefits include higher rates of high school graduation, high quality of overall health later in life, increased life-time earnings when compared to their peers, and lower rates of incarceration (García et al. 2017; Parker et al. 2019; Weiland 2018). Investing in high-quality preschool education reduces spending in multiple areas, based on these findings.

The Preschool Partnership Grant in our state, which was initiated in 2016-2017, provided funds to district grantees for the purpose of increasing access to full-day quality preschool programming through strengthening of partnerships, especially for Child Care Assistance Program (CCAP) eligible families. In 2016-2017, there were 46 out of a total 172 districts (26.7\%) participating in the grant. The total number of grantees for 2017-2018 was 79 because some districts submitted and received approval for more than one proposal. The 79 grantees consisted of 66 districts, which represents $38.4 \%$ of the total 172 school districts in the state.

Prior to the 2016-2017 Preschool Partnership Grant, district preschool programs provided half-day programs for 4-year-old from families with an income threshold of $160 \%$ or less of the federal poverty level per state regulation (704 KAR 3:410) and preschool age children with disabilities per IDEA regulation. In addition, district preschool program lead teachers were mandated to obtain Interdisciplinary Early Childhood Education (IECE) teacher certification per state regulation (16 KAR 2:040). The potential partners for the Preschool Partnership Grant (e.g., Head Start or child care program) adhered to their own regulating body guidelines. These different regulations or guidelines for each program for preschool age children made navigating the child care system for families difficult, and each entity functioned in isolation or as competitors. For example, sharing a child with a developmental delay between two programs (e.g., a child care and district preschool) would mean loss of income for the child care program during the hours this child is being served by the district preschool program. If a family needs all-day child care, transportation between programs could be an issue, as many districts did not offer transportation to child care programs but to the child's residence after the end of half-day district preschool program. The different funding sources and regulations for child care, district preschool, and Head Start programs created a complicated, fragmented early care and education system. 


\section{Review of literature}

Research shows that high-quality preschool is necessary for setting children up for success and helping to close the achievement gap (García et al. 2017). The literature also shows that the benefits of early childhood education depend on the quality of the preschool program (Gormley et al. 2005; Manning et al. 2017; Monnet 2019; Morgan 2019; Weiland and Yoshikawa 2013; Yoshikawa et al. 2016). The Preschool Partnership Grant deemed a program to be of quality if that program had achieved at least 3 STARS on the state quality rating system. Participation in this rating system is required by all early childhood programs that receive public funds (i.e., CCAP for child care, state funding for districts, and federal funding for Head Starts). The state quality rating system was developed based on state's child learning standards and research-based indicators of a quality education program, and evaluates programs based on four domains: (1) family and community engagement, (2) classroom and instructional quality, (3) staff qualifications and professional development, and (4) administrative and leadership practices (Compass Evaluation and Research, Inc. 2018). All four of these domains have a significant research base that supports their role in developing high-quality preschool programs (Espinosa 2002; Head Start Impact Study 2014; Jensen et al. 2017; Lewallen et al. 2015; Weiland and Yoshikawa 2013). In addition, all of these domains and their individual standards are supported by the majority of early childhood education stakeholders that elected to participate in the state quality rating system review (Compass Evaluation and Research, Inc. 2018).

The domain of family and community engagement assesses the number of professional development activities staff members complete related to strengthening family engagement, implementing family engagement activities, having consistent two-way communication with families, sharing community resources with families as appropriate, and building partnerships with community agencies. The domain of classroom and instructional quality measures the percentage of staff that have completed professional learning activities related to developmental screenings, whether the program completes the developmental screening with 90 days of enrollment, completes an environmental selfassessment using a valid and reliable tool, implements a curriculum that aligns with the state student early learning standards, and implements a specialized supplemental curricula. It also considers whether student early learning standards are incorporated into lesson plans, staff supports IFSP/IEP goals, and the program conducts ongoing curriculum-based assessments to inform individual and group instruction. Finally, the domain of classroom and instructional quality considers whether the program shares the assessment results with the families, participates in an environmental observation using a valid and reliable tool, and maintains NAEYC staff-to-child ratios. The domain of staff qualifications measures whether program staff receive $10 \mathrm{~h}$ of professional development in curriculum and instructional practices, staff members have an approved early childhood credential or degree, and the program administrator achieves the state director credential or the equivalent. The domain of administrative and leadership practices measures whether programs are members of an early childhood professional organization, provide teachers with weekly lesson planning time, have a system for evaluating staff performance, have a continuous improvement plan that seeks input from staff members 
and the children's family, and provide full benefits to their staff (Compass Evaluation and Research, Inc. 2018).

These domains also reflect the standards of learning recommended by the National Institute for Early Education Research (NIEER) (a) a well-implemented curriculum that supports learning and development, (b) staff members with appropriate credentials, having staff members participate in professional development activities, (c) class sizes and staff-to-child ratio within the recommend guidelines, (d) screening and support services in place, and (e) continuous monitoring for improvement in place (FriedmanKrauss et al. 2018). These standards that are based on rigorous research help differentiate high-quality programs from the rest.

The aim of the state Preschool Partnership Grant is improving the quality of preschool education. This grant seeks to incentivize public/private cooperation through partnerships between public school districts and child care providers to develop full-day highquality programs for at risk population, especially CCAP eligible children. This grant helps schools and child care programs specifically meet the state quality rating system's goal of community collaboration.

The vision and needs can be specified by each district and/or partner agency; however, grantees are encouraged to focus on a few core elements including increasing family and community engagement by providing family education and/or hosting family engagement events, aligning curriculum between the school and partner site, providing professional development opportunities and coaching to both school and partner site staff, hiring new or additional staff with the appropriate qualifications, providing a framework for how the school and partner site will continuously evaluate their performance, and expanding their current programming operation hours. Grantees are encouraged to focus on these areas as they align directly with many of the state quality rating system standards, which in turn align with the state's student early learning standards. School districts may feel confident in their ability to provide high-quality preschool education and are validated in this feeling by their current 3-STAR or higher on the state quality rating system. However, many child care centers (i.e., 59.6\%) providing 5 days a week, all-year, full-day services that allow families to work are still ranked at 1 STAR or 2 STARS according to the Early Childhood Profile (2019) (https://kystats.ky.gov/Lates t/ECP). This is where the Preschool Partnership Grant can create the most impact on quality as schools help mentor child care providers, which in turn helps provide highquality preschool experiences to more at-risk children in the state.

\section{Study framework}

In our study, we recognize that social and emotional aspects of development are interlaced with the cognitive factors of development. Other researchers (Raver and Knitzer 2002; Raver 2003; Zigler and Bishop-Josef 2006) have adopted this stance within the context of early childhood education. Furthermore, we note that emotional adjustment is a necessary precursor to cognitive and academic readiness (Raver 2003). Phillips and Shonkoff (2000) recognized the importance of early childhood environments for building a strong foundation of development for later learning, and also observed that the interactions among early childhood research, policy, and practice are problematic and demand dramatic rethinking. Raver and Knitzer's (2002) recommendations to 
policymakers stress investing in support for classrooms, families, and teachers that focus on the all areas of the child, i.e., social, emotional, and cognitive aspects of development. The whole-child approach to early childhood education is a salient piece within the context of our own case study regarding the Preschool Partnership Grant.

\section{Research questions}

In our case study, we wanted to focus on the things that the district preschool grantees were doing with their Preschool Partnership Grant funding that enabled them to address the early childhood research-to-policy-to-practice issues that were highlighted in the previous literature review. A complete list of research questions is included in Additional file 1: Appendix A. Questions addressed three broad categories. In specific, district grantees were able to foster quality preschool programming through initiating and sustaining relationships among preschool partners, including the professional development activities and interventions that enabled them to target the whole child on multiple levels? In addition, we wanted to know if district grantees were able to increase access to quality programming for preschool children from low-income families and with disabilities? Most importantly, we examined the different ways that districts went about carrying out these objectives and analyzed the importance of collaboration and trust building among partners and stakeholders.

\section{Case description}

Methodology

We conducted a quantitative case study of the Preschool Partnership Grant, using secondary, survey data analysis. This grant provided funding to districts who successfully applied for implementation funding to focus on improving the quality of preschool programs, increasing the access to their programs, and improving the kindergarten readiness of 3- and 4-year-old children enrolled in the programs. The maximum funding amount for applicants who were recipients of the 2016-2017 school-year grant was $\$ 75,000$. Districts who applied for the Preschool Partnership Implementation Grant in 2017-2018 for the first time received a maximum of $\$ 150,000$. The funding amount for the successful returning applicants in 2017-2018 ranged from $\$ 44,000$ to $\$ 75,000$. The funding amount for the successful new applicants ranged from $\$ 76,960$ to $\$ 150,000$. For our study, we examined data from the 2017-2018 grant period for school districts that received implementation state funding for preschool partnerships.

\section{Participants}

There were 66 districts out of the 172 districts in the state involved for this period, although several districts had applied for and received multiple grants from the state. This brought the total number of grantees to 79 . So there were 79 total grantees, from 66 districts, because some districts had applied for and received separate grants for multiple implementation sites. The State Department of Education and state preschool coordinators played a key implementation role at the state level, while district personnel (teachers, administrators, liaisons, and coaches), grantee partners, and associated personnel were all involved in the Preschool Partnership Grant planning and collaboration 
process at the district level. District administrators completed the survey for the current study.

\section{Survey instrument}

Survey data included quantitative items and open-ended responses that provided descriptive information regarding the districts and their partners. The survey items asked questions about different aspects of preschool quality and access to quality. The survey is included as Additional file 1: Appendix A. The State Department of Education created the survey and administered it to the school districts. The district administrators completed their responses and submitted the survey at the end of the 2017-2018 school year. The response rate was $100 \%$ across all items in the survey because every district receiving preschool partnership funds were required to complete the survey in order to receive funds. The State Department of Education provided the data to us with all identifying information removed.

Several items were quantitative in nature, and these items addressed basic descriptors of the districts and district partners, such as the type of partner working with each district, the number and type of staff funded by the grant, whether enrollment increased because of the grant, and why enrollment increased. Several, qualitative, open-ended items allowed participants to describe the nature of professional development, training sessions, and consultation or intervention services to the partnering programs, if grant funding was used for these programs.

\section{Results}

The overall indication from the district grantees regarding the Preschool Partnership Grant was positive. Many reported that various collaborative activities, made possible by funding, played a major role in the implementation and sustenance of the partnerships that fostered quality, systematic preschool programming. For example, one district noted that "common planning time between child care directors and preschool teachers" was the most essential activity that will continue. This district also commented that the "school staff providing support for curriculum development" was an integral part of ensuring high-quality centers. These are only a small sampling of the many districts that recognized the power of collaboration between partners and districts.

The district grantees were given latitude for choosing the type of partnership and their specific partner(s) for the Preschool Partnership Grant. The 79 grant recipients reported that they were engaged in a number of different partnership types via grant funding, and this information is reported by type and percentage in Table 1 . Some grantees only

Table 1 Percentage of grantees reporting on types of partnerships

\begin{tabular}{ll}
\hline Partnership type & $\begin{array}{l}\text { Percentage } \\
\text { of grantees } \\
\text { reporting }\end{array}$ \\
\hline Child care (private) & 55.7 \\
Child care (district owned/operated) & 35.4 \\
Head start & 44.3 \\
Other (various) & 12.7 \\
\hline
\end{tabular}


reported one type of partnership, while others reported more types of partnerships. Private child care sites were the most common type of partners, but district-owned sites, and Head Start sites were also reported as the key partners. Other types of partnerships included a library, an innovative blended preschool and kindergarten program, a regional cooperative, and a local collaborative.

\section{Serving more children}

One of the goals of the grant was to increase access to quality care and education for at risk populations, especially CCAP eligible children in the respective districts. Grant recipients were asked to report reasons for the increase in enrollment, and many recipients reported multiple reasons (Table 2). Improved collaboration was the number one reason for serving more children. Regarding the importance of collaboration, one district noted

"The communication and collaboration gained from this partnership have been tremendous. We are TRULY partners in educating the young children of our community. This collaboration is based on relationships and built with trust. We will continue to support our 'shared' children and their families to provide full day care."

Increased recruitment activities and partnership/program referrals were also regarded as being the key factors in being able to serve more children during the 2017-2018 grant period. When provided a chance to communicate other activities that would continue with the provided grant funding, all-day/extended programming, and personnel hiring came up as important factors in building capacity and being able to serve and touch more children's lives. Partners reported that they planned to maximize the number of students served through partnership by communicating about student-specific needs, identifying eligible students, and identifying strengths of each partner. This increase in recruitment activities and program referrals, for many of the district grantees, helped to capture children that otherwise would not have received the holistic type of wraparound support needed at this early age. Several districts reported other reasons for serving more children. They reported extending days and weekly services, increasing to full-day programs with more parents willing to send

Table 2 Reason for serving more children (based on multiple responses by grant recipients)

\begin{tabular}{ll}
\hline Reason & $\begin{array}{l}\text { Number of grant } \\
\text { recipients } \\
\text { reporting }\end{array}$ \\
\hline Partnership/program referrals & 49 \\
Child find activities & 47 \\
Increased capacity & 39 \\
Increased recruitment activities & 51 \\
Improved collaboration & 55 \\
Other & 26 \\
\hline
\end{tabular}


their children, opening a new center, and using a school liaison as "other" reasons for serving more children.

\section{Consultation or intervention services}

Ninety-six percent of the districts reported that they provided consultation or intervention services through funding. Consultation and intervention services that districts provided with the use of grant funding to partner sites were family and community engagement activities, family education efforts with the dissemination of information, literacy efforts, and resources. Several districts mentioned embedded coaching and the provision of model lesson plans and activities. Embedded coaching involved district preschool staff providing training at the partnership sites to share their knowledge with and offer guidance to staff at the various child care centers. This type of on-site provision of resources was a new format, as districts and partners often operated in separate silos prior to the Preschool Partnership Grant. The grant-funded intervention and Responseto-Intervention (RTI) services at the partner sites, designed to increase and support children's vocabulary, literacy, math, social/self-help, and other foundational skills in helping them become kindergarten ready. Interventions were designed to target those children, in which screening indicated different areas of need with respect to these different types of skills and knowledge. Some of the interventions were designed to support parents in helping their children become kindergarten ready. Many of the districts stated that intervention services and referrals were conducted in partnership with speech, occupational, and physical therapists, as well as nutritional consultants, to provide services to those children in need. At the base of these intervention services was the foundation of collaborative support that funding helped to sustain within the partnerships. Past research has recognized the importance of addressing early childhood education through a holistic lens, and has suggested that this should be a focus of future policy and funding (Raver and Knitzer 2002; Raver 2003; Zigler and Bishop-Josef 2006).

\section{Professional development activities}

Another major sector of grant fund spending involved high-quality professional development (PD) for district and partner staff. Trainers had to be credentialed by the state in order to be documented as high-quality professional development trainers. Ninety-one percent of grantees used funding for PD/Training. The number and type of staff in Table 3 represent the total number and type of staff, across all types of partnerships as reported by all 66 districts ( $n=79$ grant recipients). Districts reported that technical assistance was provided in the areas of motor development, communication, behavior, curriculum, instruction, nutrition, and family support by members of the school staff and outside personnel. Funds provided the actual professional development services and training, as well as transportation, to and from trainings, other support resources, and curricular alignment, in many cases. Despite the difference in implementation format or function of grant-funded PD/trainings by the district grantees, the grant funds made a meaningful impact in raising the skills and knowledge of all staff (teachers, assistant teachers, and administrators) to address the whole child. Professional development topics often focused on training staff in the 
Table 3 Number of staff participating in high-quality professional development

\begin{tabular}{lc}
\hline Staff type & $\begin{array}{c}\text { Number } \\
\text { of staff }\end{array}$ \\
\hline Child care teachers & 387 \\
Child care assistant teachers & 202 \\
Child care administrators & 137 \\
Preschool teachers & 397 \\
Preschool assistant teachers & 395 \\
Preschool administrators & 93 \\
Head start teachers & 107 \\
Head start assistant teachers & 91 \\
Head start administrators & 40 \\
Other & 129 \\
\hline
\end{tabular}

delivery of early math and literacy programming, STEM instruction, socioemotional development, health, and other curricular instructional topics. For example, one district stated, "A Super Saturday event was held for our child care staff and open to others in the community. Participants received $6 \mathrm{~h}$ of training in the areas of language and literacy, social emotional development, and health and wellness."

Table 4 shows the STAR rating levels for the different partnership sites at the end of the 2017-2018 grant period. Only sites at a level of 3 STARS were able to take part in the partnership grant; however, 2 STAR sites were considered, under the condition that they achieve 3 STARS at the end of the grant period. This accounts for the absence of any 1 STAR or 2 STAR sites in Table 4 . The professional development and training funded through the Preschool Partnership Grant addressed the four domains of quality preschool programming (i.e., family and community engagement, classroom and instructional quality, staff qualifications, and administrative and leadership practices) as well as focusing on holistic wellness of children. The impact of these professional development activities for staff across sites, especially child care partners, helped support achievement of higher STAR ratings. As mentioned earlier, the STAR ratings captured in Table 4 indicate the rating of the different sites including the district preschool grantees and their respective partner sites (i.e., Head Start or Child Care) at the end of the 2017-2018 school year, a single point in time. It would be helpful to have rating information at the beginning of the year for comparison purposes, but unfortunately, this information was not available. What this does indicate is that the STAR level for the district grantee preschools is higher than their partner sites, especially the child care partners. Table 4 also suggests that the professional development opportunities created through this grant were definitely needed for the

Table 4 Number of STARS for different sites supported by grant

\begin{tabular}{lccc}
\hline Site & 3 STARS & 4 STARS & 5 STARS \\
\hline District preschool & 29 & 1 & 214 \\
Head start & 13 & 7 & 37 \\
Child care & 63 & 25 & 16 \\
Total & 105 & 33 & 267 \\
\hline
\end{tabular}


partner sites' improvement in STAR rating as a result of helping to increase the qualifications, skills, and knowledge of participating staff.

\section{Challenges}

The collaborative and systematic preschool structures within the various districts that were facilitated by the Preschool Partnership Grant did not exist without their challenges. District grantees stated that certain activities would cease to exist without the additional funding to sustain these efforts. The following is a list of themes that categorize the impactful activities that were made possible through the grant but would be negatively impacted without grant funding:

- Personnel (support staff and/or certified faculty) or at least a decrease in number.

- Extended programming hours or at least reduction in operation hours.

- Professional development opportunities.

- Intervention and other types of support.

- Information for families.

- Resources and transportation or at least reduced capacity.

Not all districts reported that they were considering cuts in these areas, but districts have many different needs to fulfill, and sometimes they have to make the unfortunate choice to eliminate services and other types of support, in order to scale back to minimum functional programming. Partners also reported several challenges, including the issues of coordination of schedules, finding time to meet that worked for both programs' schedules, and creating a shared vision.

Many district grantees indicated that certain activities would continue into the next school year regardless of funding, suggesting that grant funding initially provided a spark by which programming and other efforts began and that these efforts will continue through other means. In addition, most districts indicated that improved collaboration was the main reason for serving more children during the current grant period. This supports the idea that collaboration is very important, and tends to carry over and support many of the other activities, highlighted as successes due to increased funding. Collaboration seems to have a perpetual effect in which the whole of the positive outcomes is greater than the sum of the different inputs.

\section{Discussion}

In this discussion, we address our research questions. The first question asked whether districts were able to foster quality preschool programming through initiating and sustaining relationships among preschool partners, including the professional development activities and interventions that enabled them to target the whole child on multiple levels. The district grantees who tended to have partners at a 5-STAR level, reported in their survey responses that embedded coaching and professional development activities were big components of the Preschool Partnership Grant funding expenditure. To be at the 5-STAR level, preschools have to score at high levels among the domains of family and community engagement, classroom and 
instructional quality, staff qualifications and PD, administrative, and leadership practices (Governor's Office of Early Childhood 2016). The districts provided technical assistance related to curriculum, family support, meeting children's developmental and health needs, as well as variety of interventions including RTI to their partners. As noted in "Results" sections, the grant funding was used to better inform partner teachers about how to provide instruction that addressed children's academic and non-academic needs (i.e., the whole child focus) through professional development. School districts typically would not think about providing training to their teachers on Saturday, but district grantees did offer 1-day Saturday training through the grant funds because this format made better sense for their partner staff, especially their child care partners. The district grantees indicated that these grant-funded activities, especially embedded, on-site coaching, would be difficult to continue after the grant because of the need for funding to pay district personnel who assume the responsibilities of coaching. Other professional development activities (i.e., training hours) may not be able to be sustained at the same level as with the grant funding. However, the partner staff may be more likely to participate in future trainings that school districts offer to their staff, and open to the community due to the established relationships between the district grantees and their respective partners, resulting in familiarity and a greater comfort level for the partner staff.

Our second research question asked whether districts were able to increase access to quality programming for preschool children from low-income families and with disabilities. Since the Preschool Partnership Grant implementation, the total number of preschool children served in the state by districts did increase despite reduction in state funding per preschool child for the districts. In 2015-2016, the district preschool programs received $\$ 4832$ per child and served 19,182 children, representing $26 \%$ of total 4-year-old and 9\% of total 3-year-old (Barnett et al. 2017). In comparison, the district preschool programs received $\$ 4514$ per child in 2017-2018 and served total of 21,270 children, representing $29 \%$ of total 4-year-old and $10 \%$ of total 3-year-old in the state (Friedman-Krauss et al. 2019). The Preschool Partnership Grant cannot be deemed as the only explanation for the increase in number of low-income children and children with disabilities as the state reduced its preschool funding to school districts. However, the reports from the grant recipients do suggest potential effectiveness of the Preschool Partnership Grant as a contributing factor for the slight increase.

District grantees reported that they did increase their overall preschool enrollment in 2017-2018 as compared to their overall preschool enrollment number in 2016-2017. The district grantees indicated their collaboration with their respective partners was the primary reason allowing them to serve more children in 2017-2018. Other reasons provided by the district grantees were their recruitment efforts, referrals from their partners, being able to screen children on-site, as well as providing RTI at their respective partner programs. The grant funding helped with Child Find efforts, especially with the 3-year-old. As noted at the beginning of this paper, 3-year-old are only eligible for the district preschool if they have a developmental delay (DD) and not based on meeting the $160 \%$ of the federal poverty level in family income. The process to determine whether a 3-year-old has a DD requires initial screening and RTI implementation. The screening and RTI implementation at partner sites contributed to identifying 3-year-old with DD, 
who then were enrolled in district preschools where they could receive special education services. This grant funding also helped district grantees work with their respective partners in sharing CCAP eligible 4-year-old who were already attending child care partner sites but may not have been identified for DD. The collaboration with partner sites assisted district grantees with their Child Find efforts. Therefore, the positive impact of collaboration among different entities involved with the Preschool Partnership Grant demonstrates the need for funding holistic approaches that re-envision the early care and education system.

Finally, we examined the different ways that districts carried out their objectives, and analyzed the importance of collaboration and trust building among partners and stakeholders. The collaborative relationships formed through the district preschool partnerships support the research, which suggests that alignment among policies and programming, as well as the relationships and positive climate produced from increased collaboration at the district and classroom level, are necessary for making positive impacts on children's' learning (Reynolds and Temple 2019; Manning et al. 2017). One district noted the importance of being a "true" partner. They also spoke of their "shared" children in the community. This perspective was the result of the evolution of the partnership built on trust and relationships.

One area of collaboration occurring through the partnerships that would not have occurred otherwise was the collaborative child-find efforts. Increased collaboration was one of the chief reasons that districts were able to find more children in their communities. Communicating about student-specific needs, identifying eligible students, and identifying strengths of each partner were crucial components that led to increased enrollment numbers of eligible children. It is clear that many of the districts and partners viewed screening and recruitment as a dual effort, and even though they had not operated this way in the past, the grant allowed them to try new ways of approaching this issue. Districts often provided technical assistance during trainings to partner staff, across many topics, and curricular alignment was often the goal for many of the partnerships. The data suggest that districts and partners often moved to work in unison rather than as separate entities as they had done in the past. One might like this to becoming more of a well-oiled machine that, as a whole, is greater than the sum of its parts.

\section{Conclusion}

The districts that received Preschool Partnership Grant funding during 2017-2018 were doing well. The districts engaged in the activities and collaborative efforts with their partner sites that allowed them to address early childhood education from a whole-child approach (Crosnoe et al. 2015; Puma et al. 2010), which has allowed them to sustain quality, building efforts within their preschool programming across all participating sites. These types of quality programming are recognized as essential for making a positive impact on the success and well-being of young children (Gormley et al. 2005; Meloy et al. 2019; Morgan 2019; Weiland and Yoshikawa 2013). The efforts by many of the participating districts were aligned with state standards for preschool quality (Compass Evaluation and Research, Inc. 2018), as well as national standards as set forth by the National Institute for Early Education Research (Espinosa 2002). These efforts and the positive impacts they made on the children across the state may stop, or may be harder 
to implement without future funding. Other researchers also recognized the need for funding (Raver and Knitzer 2002), and the positive difference that it makes on quality of programs, teacher quality, and resources available to children (Friedman-Krauss et al. 2018; Kolomeyer 2018). More importantly, funding will help to support the sustainability of the preschool partnerships and, hopefully, keep what has been built up to this point from unraveling.

Future directions and sustainability plans involve examining the specific things occurring in the district partnerships, and their specific contributions to the lasting effect on children's well-being at all levels of functioning. It will be important to analyze what districts are doing well and what can be generalized, or replicated, across other districts. Communication among districts, state policy makers, program evaluators, and other stakeholders will be essential to helping sustain the quality, collaborative preschool practices taking place that will ultimately uphold the success and well-being of children throughout the lifespan. Many of the districts and their partners would have to cease many of the positive initiatives, layoff staff, and possibly decrease enrollment or childfind efforts, if future funding rounds are not provided.

Approaching early care and education from a systematic and holistic perspective (i.e., whole-child) requires keeping the focus of funding on characteristics that contribute to disparity. Factors such as disability and poverty can negatively impact a child's learning and development as well as families' resiliency or well-being. A family's household income level as well as the child's disability can be traumatic to the functioning of the family as a unit as well as individual family members. Furthermore, research points to the lack of opportunity for children from low-income families and children with disabilities to attend high-quality preschool programs. The state data for 2018 indicate 163,321 $(50.8 \%)$ children aged 6 years or younger lived below $200 \%$ of federal poverty level, and 28,678 children were serviced through CCAP (Early Childhood Profile 2019). In addition, $49 \%$ of the district preschool 3- and 4-year-old in 2018 had disabilities and 42\% were 4-year-old who qualified based on family's low-income (Early Childhood Profile 2019). Despite the increase in number of children being served through the 2017-2018 Preschool Partnership grantees with wraparound quality programming, the 2018 data for the state demonstrate more work still needs to be completed to support children and families who are "at-risk" toward well-being. Families' resiliency and their ability to combat stressors necessitate that all who touch children's' lives work together with families in offering "family-centered, trauma-specific services that put families in the 'driver's seat' and empower them" (The National Child Traumatic Stress Network 2011, p. 2). Therefore, the integration of the early childhood programs, policies, and practices need to be sustained to make a lasting positive impact on the lives of young children (Reynolds and Temple 2019). Continuing funding of the Preschool Partnership Grant is needed, and bigger impacts could result if more districts apply and receive funding. Future, longitudinal studies examining statistics on districts that participate in the Preschool Partnership Grant program versus districts that do not participate in the program may help to strengthen the argument for future funding, if the grant programming shows significant benefits for participating versus non-participating districts. A more effective avenue to a holistic, systematic, "whole-child" focused outcome, and sustainable approach would be for the state to integrate the Preschool Partnership Grant criteria to all early care 
and education systems where any entity touching the lives of children and their families would be required to collaborate in order to create a synergy of options that align best with families' work needs or any type of trauma-related stress needs. This type of approach would align with other policies focused on holistic strategies for helping children thrive, e.g., the Strengthening Families framework (The Center for the Study of Social Policy 2019) and giving families the resources that make this possible. A resilient family will better be able to help their children with self-regulation and higher executive functioning, which would result in better academic outcomes, as well as more positive school experiences for their children.

\section{Supplementary information}

Supplementary information accompanies this paper at https://doi.org/10.1186/s40723-019-0065-6.

Additional file 1. Preschool partnership end-of-year survey 2017-2018.

Abbreviation

CCAP: Child Care Assistance Program

Acknowledgements

This research was supported by the Kentucky Department of Education.

Authors' contributions

All authors made significant contributions to this manuscript. All authors contributed to the theoretical framework and gave approval for submission of this manuscript. RA contributed to the literature review, methodology, results, and discussion. LG made substantial contributions to the literature review and background. JG proofread and made substantial revisions to the background, literature review, and conclusion. All authors read and approved the final manuscript.

\section{Funding}

The study was funded by the Kentucky Department of Education and the Preschool Partnership Grant. The funding body contributed to the collection of data, but played no role in the analysis of data or writing of the manuscript.

\section{Availability of data and materials}

The data that support the findings of this study are available from the Kentucky Department of Education but restrictions apply to the availability of these data, which were used under license for the current study, and so are not publicly available. Data are however available from the authors upon reasonable request and with permission of the Kentucky Department of Education.

\section{Competing interests}

The authors declare that they have no competing interests.

\section{Author details}

${ }^{1}$ Department of Teacher Education, MEP 273, Nunn Drive, Highland Heights, KY 40199, USA. ${ }^{2}$ Department of Social Work, 100 Nunn Drive, Highland Heights, KY 40199, USA. ${ }^{3}$ Department of Teacher Education, MEP 280, Nunn Drive, Highland Heights, KY 40199, USA.

Received: 24 June 2019 Accepted: 26 November 2019

Published online: 05 December 2019

\section{References}

Barnett, W. S., Friedman-Krauss, A. H., Weisenfeld, G. G., Horowitz, M., Kasmin, R., \& Squires, J. H. (2017). The State of Preschool 2016: State Preschool Yearbook. New Brunswick, NJ: National Institute for Early Education Research.

Compass Evaluation and Research, Inc. (2018). Kentucky's ALL STARS Validation Study: Interim Findings Report for the Early Childhood Advisory Council. Durham: Compass Evaluation and Research Inc.

Crosnoe, R., Bonazzo, C., \&Wu, N. (2015). Healthy learners: A whole child approach to reducing disparities in early education. New York: Teachers College Press.

Early Childhood Profile 2019. Retrieved from https://kystats.ky.gov/Latest/ECP.

Espinosa, L. M. (2002). High-Quality Preschool: Why We Need It and What It Looks Like. NIEER Preschool Policy Matters, Issue 1. Retrieved from https://search.ebscohost.com/login.aspx?direct=true\&db=eric\&AN=ED480 $816 \&$ site=eds-live.

Friedman-Krauss, A. H., Barnett, W. S., Garver, K. A., Hodges, K. S., Weisenfeld, G. G., \& DiCrecchio, N. (2019). The State of Preschool 2018: State Preschool Yearbook. New Brunswick, NJ: National Institute for Early Education Research.

Friedman-Krauss, A. H., Barnett, W. S., Weisenfeld, G. G., Kasmin, R., DiCrecchio, N., \& Horowitz, M. (2018). The State of Preschool 2017: State Preschool Yearbook. New Brunswick, NJ: National Institute for Early Education Research. 
García, J. L., Heckman, J. J., Leaf, D. E., \& Prados, M. J. (2017). Quantifying the life-cycle benefits of a prototypical early childhood program (No. w23479). National Bureau of Economic Research.

Gormley, W. T., Gayer, T., Phillips, D., \& Dawson, B. (2005). The effects of universal pre-K on cognitive development: Development psychology and public policy. Developmental Psychology, 6, 872. Retrieved from https://search.ebscohost. com/login.aspx?direct=true\&db=edsfra\&AN=edsfra. 17309140\&site=eds-live.

Governor's Office of Early Childhood. (2016). Kentucky All Stars. Retrieved November 14, 2019, from https://kentuckyal Istars.ky.gov/Pages/index.aspx.

Head Start Impact Study. (2014). Congressional Digest, 93(4), 5. Retrieved from https://search.ebscohost.com/login .aspx?direct $=$ true \&db $=$ f5h\&AN=95423426\&site $=$ eds-live.

Jensen, B., Jensen, P., \& Rasmussen, A. W. (2017). Does professional development of preschool teachers improve children's socio-emotional outcomes? Labour Economics, 45, 26-39. https://doi.org/10.1016/j.labeco.2016.11.004.

Kolomeyer, E. (2018). The State of Trauma-Informed Care in the Preschool.

Lewallen, T. C., Hunt, H., Potts-Datema, W., Zaza, S., \& Giles, W. (2015). The whole school, whole community, whole child model: a new approach for improving educational attainment and healthy development for students. Journal of School Health, 11, 729-739.

Manning, M., Garvis, S., Fleming, C., \& Wong, G. T. (2017). The relationship between teacher qualification and the quality of the early childhood care and learning environment. A Campbell Systematic Reviews. https://doi.org/10.4073/ csr.2017.1.

Meloy, B., Gardner, M., \& Darling-Hammond, L. (2019). Untangling the evidence on preschool effectiveness: Insights for policymakers. Palo Alto, CA: Learning Policy Institute.

Monnet, J. (2019). The effect of preschool participation on intellectual and behavioral disorder diagnoses: Evidence from surveys on children's health. Economics of Education Review, (C), 136. Retrieved from https://search.ebscohost. com/login.aspx?direct=true\&db=edsrep\&AN=edsrep.a.eee.ecoedu.v68y2019icp136.147\&site=eds-live.

Morgan, H. (2019). Does high-quality preschool benefit children? What the research shows. Education Sciences, 9(1), 1-9.

Parker, E., Keily, T., Atchison, B., \& Mullen, J. (2019). Trends in Pre-K Education Funding in 2017-2018.

Phillips, D. A., \& Shonkoff, J. P. (2000). From neurons to neighborhoods: The science of early childhood development. Washington, D.C.: National Academies Press.

Puma, M., Bell, S., Cook, R., Heid, C., Shapiro, G., Broene, P.,... \& Ciarico, J. (2010). Head Start Impact Study. Final Report. Administration for Children \& Families.

Raver, C. C. (2003). Young children's emotional development and school readiness. ERIC Digest. ED 477641. Retrieved from https://eric.ed.gov/?id=ED477641.

Raver, C. C., \& Knitzer, J. (2002). Ready to enter: What research tells policymakers about strategies to promote social and emotional school readiness among three- and four-year-old children.

Reynolds, A. J., \& Temple, J. A. (2019). Sustaining early childhood learning gains: Program, school, and family influences. Cambridge: Cambridge University Press.

The Center for the Study of Social Policy. (2019). Strengthening Families. Retrieved November 13, 2019, from https://cssp. org/our-work/project/strengthening-families/.

The National Child Traumatic Stress Network. (2011). Trauma and Families: Fact Sheet for Providers. Retrieved from http:// wWw.NCTSN.org.

Weiland, C. (2018). Commentary: pivoting to the "how": Moving preschool policy, practice, and research forward. Early Childhood Research Quarterly, 45, 188-192. https://doi.org/10.1016/j.ecresq.2018.02.017.

Weiland, C., \& Yoshikawa, H. (2013). Impacts of a prekindergarten program on children's mathematics, language, literacy, executive function, and emotional skills. Child Development, 84(6), 2112. https://doi.org/10.1111/cdev.12099.

Yoshikawa, H., Weiland, C., \& Brooks-Gunn, J. (2016). When Does Preschool Matter? Future of Children, 26(2), 21-35. Retrieved from https://search.ebscohost.com/login.aspx?direct=true\&db=eric\&AN=EJ1118535\&site=eds-live.

Zigler, E. F., \& Bishop-Josef, S. J. (2006). The cognitive child versus the whole child: Lessons from 40 years of Head Start. Play = learning: How play motivates and enhances children's cognitive and social-emotional growth, pp. 15-35.

\section{Publisher's Note}

Springer Nature remains neutral with regard to jurisdictional claims in published maps and institutional affiliations.

\section{Submit your manuscript to a SpringerOpen ${ }^{\circ}$ journal and benefit from:}

- Convenient online submission

- Rigorous peer review

- Open access: articles freely available online

- High visibility within the field

- Retaining the copyright to your article

Submit your next manuscript at $\boldsymbol{\Delta}$ springeropen.com 